\section{SP5-10 KNOWLEDGE OF HIV/AIDS AND REPRODUCTIVE HEALTH AND SELF-REPORTED SEXUAL BEHAVIOURS AMONG SENIOR HIGH SCHOOL STUDENTS IN PAPUA AND WEST PAPUA PROVINCES, INDONESIA}

doi:10.1136/jech.2011.142976p.46 light and only fireplace at night. The case's houses were located close to the breeding habitat and within a flight range of Anopheles. A more systematic and sustainable health education program is needed to raise public health awareness. The use of Long Lasting Insecticide Nets is the best choice for this area.

\section{SP5-12 OUTBREAK OF CHOLERA, EAST-AKIM MUNICIPALITY, GHANA, NOVEMBER 2010}

doi:10.1136/jech.2011.142976p.48

Papua and West Papua Provinces have the highest prevalence of HIV/AIDS in Indonesia. In 2009, 94.4\% HIV/AIDS cases in Papua Province were transmitted through heterosexual intercourse and HIV/AIDS cases among 15-19 years of age were in the fourth rank. A study in 2007 revealed 46.9\% Junior High School students in the province had misconception on HIV/AIDS transmission and prevention. Previous studies also found high-risk sexual behaviours in some Papuan cultures, including multiple sex partners and early initiation of sexual activity. These features motivated the first author to carry out the 2009. Reducing the Risk of HIV/AIDS: Intervention Trial for Young Papuans Study. 16 Senior High Schools were randomly selected and agreed to participate to either receive the HIV/AIDS and reproductive health program or act as a control group. Students of Year 11 from the selected schools $(\mathrm{N}=1082)$ took a pre test and 2 months later, a post-assessment test. The aim of this study was to analyse the association between knowledge of $25 \mathrm{HIV} /$ AIDS and reproductive health questions on the pre test and the self-reported sexual behaviours before the intervention. We also used qualitative method to explore perspectives and experiences on sexuality. Results showed more than 50\% students had limited knowledge on HIV testing, safe sex and STDs prevention. Although female students had better knowledge test and demonstrated less sexual intercourse experiences ( $28.5 \%$ compared to $46.5 \%$ of males), they carried a more unfavourable condition related to the impact of premarital sex, including pregnancy and unsafe abortion.

\section{SP5-11 HIGHLAND MALARIA OUTBREAK IN HOMEYO DISTRICT, PAPUA PROVINCE, INDONESIA: AN ENTOMOLOGICAL INVESTIGATION}

doi:10.1136/jech.2011.142976p.47

\author{
${ }^{1}$ A Oktavian, ${ }^{*}{ }^{1} \mathrm{H}$ Kawulur, ${ }^{1} \mathrm{M}$ Widiyanti, ${ }^{1} \mathrm{M}$ Raharjo, ${ }^{1} \mathrm{~L}$ Salim, ${ }^{2} \mathrm{D}$ Triboewono. \\ ${ }^{1}$ National Institute of Health Research and Development for Biomedicine, Papua \\ Province, Jayapura, Indonesia; ${ }^{2}$ Research and Development Centre for Vector and \\ Disease Reservoirs, Salatiga, Indonesia
}

The first highland malaria outbreak and associated deaths was reported in May 2010 from several villages in Homeyo District, Papua Province. Homeyo is $1900 \mathrm{M}$ above sea level with $15-25^{\circ} \mathrm{C}$ air temperature, an uncommon condition for mosquitoes to breed. The epidemiological and parasitological survey in June 2010 conducted by the Papua Health Department found Plasmodium Falciparum Rate (PFR) in Bamba, Sanepa, Pogapa and Degesiga villages were $44.23 \%, 6.73 \%, 20.27 \%$ and $7.40 \%$, respectively. Based on verbal autopsy, the team found 36 death cases due to malaria suspect. The entomological survey was intended to identify the species and breeding habitat of suspected mosquito vectors, and the distribution of the highland malaria cases related to the village location and human behaviour. The survey was carried out from 30 August to 3 September 2010. We collected larva and adult stage mosquitoes, malaria case mapping with GPS, environmental observation, short interview and blood test. Although neither larva nor adult stage of Anopheles spp. was caught due to the heavy rain and limited time of survey, the opening of new land program were likely to play an important role in creating a new mosquito breeding site. Further, the indigenous Papuan live in traditional houses, without window and
1,2 J Opare, * 1,2 J Der, ${ }^{1} \mathrm{~K}$ Afakye, ${ }^{1,2} \mathrm{G}$ Bonsu, ${ }^{1} \mathrm{C}$ Ohuabunwo, ${ }^{1} \mathrm{E}$ Afari, ${ }^{1} \mathrm{~F}$ Wurapa, ${ }^{1} \mathrm{~S}$ Sackey. ${ }^{1}$ Ghana Field Epidemiology and Laboratory Training Programme, School of Public Health, Legon, Accra, Greater Accra Region, Ghana; ${ }^{2}$ Ghana Health Service, Ghana, Accra, Greater Accra Region, Ghana

Background Cholera is an acute infectious illness with profuse watery diarrhoea caused by toxigenic Vibrio cholerae serogroup $\mathrm{O} 1$ or 0139. In Ghana, over 9000 cholera-cases with 250 deaths were recorded in 1999. On 29 October 2010, the East-Akim Municipality (EAM) received a report of suspected cholera outbreak. We investigated to characterise the outbreak, and implement control and preventive measures.

Methods We interviewed health workers, reviewed medical records, conducted environmental assessment and obtained water and stool samples for laboratory test. A descriptive study followed by unmatched case-control study was conducted. A suspected choleracase was a person with acute watery diarrhoea, with or without vomiting in EAM from 1 October to 20 November 2010. We analysed data descriptively and risk factors were identified using $\chi^{2}$ test at $95 \%$ confidence level.

Results Of 136 case-patients, 77 (56.6\%) were males. Index-case occurred on October 13th, and case-patients peaked (18.4\%) 2 November. Attack rate was $2 / 1000$ population; no death. Ages

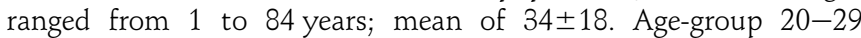
(30.1\%) was mostly affected with Tafo Sub-Municipality having most case-patients (19.9\%). V cholerae serotype ogawa was isolated from stool samples. We observed pollution of River-A with sandwashings by small-scale miners. Compared to controls, case-patients were more likely to have drunk from River-A. [OR 5.80, 95\% CI 2.45 to 13.74$]$

Conclusion $V$ cholerae serotype ogawa caused the EAM choleraoutbreak affecting mostly young adult-males. Drinking water from contaminated River-A was the major risk-factor. Boiling or chlorination of water was initiated based on our recommendations and this controlled the outbreak.

\section{SP5-13 SOCIOECONOMIC ASPECTS ASSOCIATED TO MALARIA IN PREGNANCY IN COLOMBIA}

doi:10.1136/jech.2011.142976p.49

1,2J G P Jiménez, ${ }^{2}$ S B Trujillo, ${ }^{1} \mathrm{~F}$ de la Hoz. ${ }^{1}$ Universidad Nacional de Colombia, Bogotá D.C, Colombia; ${ }^{2}$ Universidad de Antioquia, Medellín, Antioquia, Colombia

Background Income, education, work and access to prevention measures have been identified as socioeconomic aspects related to malaria. For groups at risk such as pregnant women these aspects are little known, particularly outside Africa. The objective of this study was to determine socioeconomic aspects of pregnant women associated to malaria in a Latinamerican region.

Methods A case-control study was conducted from April 2005 to December 2006 in unstable transmission malaria region. Case was pregnant who had positive thick blood smear for Plasmodium during antenatal care or delivery. Data were collected by physician using a structured questionnaire that enquired about education, 
employment and income, housing and basic services, social security and access to malaria prevention measures. Data were analysed using SPSS version 17.0.

Results 115 cases and 63 controls were interviewed. Income $<1$ USD per day, $<3$ years of school, marital status single, single-parent family, without social security and no bed-nets in house were not associated to malaria in pregnancy in bivariate analysis $(\mathrm{p}>0.05)$. Pregnant women who had a farmer as a family member (OR 2.39, $95 \%$ CI 1.12 to 5.13 ), bodies of water around the house (OR $4.66,95 \%$ CI 2.24 to 9.66), house roof made of palm tree leaves (OR 2.45, 95\% CI 1.16 to 5.15 ) were more likely to have had malaria in multivariate analysis.

Conclusion In rural areas of Colombia where poverty is very common quality of house and access to basic public services explain better social differences of pregnant women that are related with malaria frequency.

\section{SP5-14 A STUDY TO DETERMINE THE KNOWLEDGE AND PRACTICE OF FOOT CARE IN PATIENTS WITH CHRONIC DIABETIC ULCERS}

doi:10.1136/jech.2011.142976p.50

\begin{abstract}
${ }^{1,2} \mathrm{C}$ V M Jinadasa, ${ }^{*}{ }^{1} \mathrm{M}$ Jeewantha. ${ }^{1}$ Faculty of Medicine University of Colombo, Colombo, Sri Lanka; ${ }^{2}$ Sri Jayawardhanapura Hospital, Colombo, Sri Lanka
\end{abstract}

Introduction Diabetic foot ulcers account for many hospital admissions and is a major cause of amputations. This is preventable by effective identification, education and preventive foot care practice. Objective Determine the level of knowledge and practice of foot care among patients with chronic diabetic foot ulcers.

Methodology Individuals with diagnosed diabetic foot ulcers $(n=110)$ were selected from National Hospital of Sri Lanka for this descriptive study. They were given an interviewer administered, pretested questionnaire. Patient perceptions of foot care were enquired. A scoring system ranging from 0 to 10 was employed to analyse the responses given for level of knowledge and practice of diabetic foot care.

Results Mean age was 58.4 years (SD \pm 8.6 ) and $57.3 \%$ were males. Non-healing ulcers were present among $82.7 \%$ and amputations amounted to $38.2 \%$. The control of diabetes was poor in $60 \%$. Regarding foot care knowledge, the mean score was $8.37,75.5 \%$ had scored above mean and $52.7 \%$ were aware of all principles of foot care. Regarding foot care practices, the mean score was $4.55,47.3 \%$ participants had scored below mean and $22.7 \%$ did not practice any foot care principle and hence scored 0 . A Statistically significant difference exists between the foot care knowledge and practice scores $(p<0.001, z=-8.151) .51 \%$ have not been educated prior to the occurrence of complications.

Conclusion Results demonstrate a satisfactory knowledge on diabetic foot care but practices of preventive techniques were unsatisfactory. Good patient follow-up to increase compliance would help to improve this situation.

\section{SP5-15 "KNOWLEDGE-ACTION GAP" AMONG BANGLADESHI TYPE 2 DIABETIC SUBJECTS}

doi:10.1136/jech.2011.142976p.51

${ }^{1} \mathrm{~F}$ Saleh, ${ }^{*}{ }^{1} \mathrm{~F}$ Ara, ${ }^{2} \mathrm{~F}$ Khan, ${ }^{3} \mathrm{~L}$ Ali. ${ }^{1}$ Department of Community Nutrition, Bangladesh Institute of Health Sciences (BIHS), Dhaka, Bangladesh; ${ }^{2}$ DCT, Sanofi-aventis Bangladesh Ltd, Dhaka, Bangladesh; ${ }^{3}$ Department of Biochemistry \& Cell Biology, Bangladesh Institute of Health Sciences (BIHS), Dhaka, Bangladesh

Introduction The association of knowledge against actual practice has not been properly investigated in the BIRDEM (a tertiary care hospital of BADAS). The aim of this study was to assess the level of knowledge about type 2 diabetes mellitus (T2DM) and to see the association between knowledge and action among T2DM patients.

Methods An analytical cross-sectional design. A total of 500 patients withT2DM (M 58\%, age $49.4 \pm 8.8$ years) were selected from the outpatient department. Knowledge score was categorised as poor $(<45 \%)$, fair $(45-60 \%)$ and good $(>60 \%)$ on the basis of education criteria in our 10th and 12 th grade public examinations.

Results The levels of knowledge were poor in $45 \%$, fair in $47 \%$ and good in $9 \%$ of the study subjects. Only $12 \%$ subjects had good level of $\mathrm{HbA1c}$. Among them the levels of knowledge were poor in $44 \%$, fair in $48 \%$ and good in $8 \%$. About $24 \%$ subjects belonged to fair HbA1c level and the levels of knowledge were poor in 39\%, fair in $52 \%$ and good in $9 \%$ among these subjects. More than half of the subjects $(64 \%)$ had poor glycaemic status. In this group the levels of knowledge were poor in $46 \%$, fair in $45 \%$ and good in $9 \%$. A significant negative association was found between total knowledge score and HbA1c level $(r=-0.08, p=0.05)$.

Conclusion There is a knowledge-action gap in Bangladeshi T2DM subjects which may indicate largely ineffective education programs. Patient empowerment may facilitate better control of diabetes.

\section{SP5-16 TOWARDS INTEGRATION OF UNCONVENTIONAL MEDICINES IN THE PUBLIC HEALTH SERVICE: THE EXPERIENCE OF ROHINGYA REFUGEES' IN BANGLADESH}

doi:10.1136/jech.2011.142976p.52

${ }^{1,2} \mathrm{~A} \mathrm{H}$ Mollik, ${ }^{*} \mathrm{~K}$ Akter, ${ }^{2} \mathrm{~N}$ K Azam, ${ }^{3} \mathrm{~F}$ B Hossain, ${ }^{4} \mathrm{H}$ Rahman, ${ }^{5} \mathrm{~K}$ B T M Chowdhury, ${ }^{6} \mathrm{D}$ Sen, ${ }^{2} \mathrm{R}$ McField. ${ }^{1}$ Peoples Integrated Alliance, Dhaka, Bangladesh; ${ }^{2}$ Practical Academy on Wise Education and Research Foundation, Dhaka, Bangladesh; ${ }^{3}$ South Asian Women's Rights Organization, Scarborough, Ontario, Canada; ${ }^{4}$ Stamford University Bangladesh, Dhaka, Bangladesh; ${ }^{5}$ Biogene Life Care, Dhaka, Bangladesh; ${ }^{6}$ State College of Health Sciences, Dhaka, Bangladesh

Introduction Bangladesh hosts more than 200000 Rohingya refugees from Myanmar. With no changes inside Myanmar in sight, Bangladesh must come to terms with the long-term needs of all the Rohingya refugees' in the country, and allow international organisations to expand services that benefit the Rohingya refugees as well as local communities. We therefore conducted a survey of plants used by the traditional healers in the Rohingya refugees' of Bangladesh.

Methods In-depth information regarding plants type, preparation of medicines, ailments for which they are used, dosages, and side effects if any, were obtained from the traditional healers. Plant samples were collected, and identified at the Bangladesh National Herbarium.

Results A total of 13 plants were collected, which were used to treat common ailments like coughs, colds, fevers, and dermatitis infections as well as a number of other diseases like gastritis, epilepsy, gynaecology, and hepatitis. The plant names obtained in our survey included Nigella sativa L., Arachis hypogaea L., Asteracantha longifolia Nees., Gendarussa vulgaris Nees., Brassica napus L., Vitex negundo L., Clerodendrum indicum (L.) Kuntze, Achyranthes aspera L., Wedelia chinensis (Osbeck) Merr., Melia azadirachta L., Paederia foetida L., Swertia chirata (Wall.) C. B. Clarke, and Colocasia esculenta (L.) Schott.

Conclusion Since the Rohingya refugees' patients appeared to be generally satisfied with the treatment offered through these plants, they do not have to visit modern medical practitioners. It is important to conduct proper scientific studies towards discovery of compounds of interest in these plants, which can be used as safe and effective medicines. 